\title{
PEMBUATAN BUKU SAKU MATERI KEANEKARAGAMAN MAKHLUK HIDUP DI SMPIT FAJAR ILAHI BATAM TAHUN PELAJARAN 2016/2017
}

\author{
Hendra Saputra ${ }^{1}$, Nurhaty Purnama Sari ${ }^{2}$ \\ Program Studi Pendidikan Biologi, Fakultas Keguruan dan Ilmu Pendidikan, Universitas Riau \\ Kepulauan, Batam, Indonesia. \\ Email: ${ }^{1}$ hsaputra.asti@gmail.com, ${ }^{2}$ nurhatypurnamasari@gmail.com
}

\begin{abstract}
This research aims to made pocket book subject the variety of creature for the seventh students of SMPIT Fajar Ilahi Batam the year 2016/2017, to know the suitability of pocket book according to subject experts, media expert and science subject, to know student assessment for pocket book subject the variety of creature as lesson media. In this research is used research and development model through ADDIE conducted were only three steps; Analysis, Design and Development or Production. The collection data will be conducted using inquiry and interview. The expert assessment result gained validity 80.00 included valid categorize, media expert gained validity score 74.29 included in valid enough, science teacher gained validity score 79.03 included in valid enough categorize and students assessment on the trial at the field by the score 90.11 included in reasonable categorize.
\end{abstract}

Keywords: pocket book, subject the variety of creature.

\begin{abstract}
Abstrak
Penelitian ini bertujuan untuk membuat buku saku materi Keanekaragaman Makhluk Hidup untuk siswa kelas VII SMPIT Fajar Ilahi Batam Tahun Pelajaran 2016/2017, mengetahui kelayakan buku saku menurut penilaian ahli materi, ahli media, dan guru mata pelajaran IPA, mengetahui penilaian siswa terhadap buku saku materi Keanekaragaman Makhluk Hidup sebagai media pembelajaran. Dalam penelitian ini digunakan model penelitian dan pengembangan melalui ADDIE yang dilakukan adalah tiga tahap saja yaitu tahap Analysis, Design, dan Development or Production.Pengumpulan data dilakukan dengan angket dan wawancara. Hasil penilaian ahli materi diperoleh nilai validitas 80,00 yang termasuk dalam kategori valid, ahli media diperoleh nilai validitas 74,29 yang termasuk dalam kategori cukup valid, guru mata pelajaran IPA diperoleh nilai validitas 79,03 yang termasuk dalam kategori cukup valid dan penilaian siswa pada uji coba lapangan dengan nilai validitas 90,11 yang termasuk dalam kategori layak.
\end{abstract}

Kata Kunci: buku saku, materi keanekaragaman makhluk hidup.

\section{PENDAHULUAN}

Setiap satuan pendidikan berdasarkan pada Peraturan Pemerintah Republik Indonesia Bab IV Pasal 19 tentang Standar Proses (Peraturan Pemerintah RI, No.19 Tahun 2005) disebutkan bahwa satuan pendidikan harus melakukan perencanaan proses pembelajaran agar dapat berjalan secara efektif 
dan efisien. Dalam sebuah Rencana Pelaksanaan Pembelajaran (RPP) umumnya berisi identitas pembelajaran, standar kompetensi, kompetensi dasar, tujuan pembelajaran, indikator, materi ajar, metode pembelajaran, kegiatan pembelajaran, alat dan sumber belajar, serta penilaian hasil belajar. Sumber belajar merupakan salah satu komponen penting dalam proses pembelajaran karena berisikan materi ajar yang akan digunakan sebagai acuan peserta didik dan pendidik dalambelajar.

Salah satu tugas pendidik adalah menyediakan suasana belajar yang menyenangkan. Peraturan Menteri Pendidikan Nasional tentang Standar Kualifikasi Akademik dan Kompetensi Guru (Permendiknas, No.16 Tahun 2007) menyebutkan bahwa pendidik untuk SMP/MTs harus memiliki kompetensi pedagogik diantaranya menggunakan media pembelajaran atau sumber belajar atau bahan ajar yang relevan dengan peserta didik dan mata pelajaran yang diampu agar tujuan pembelajaran dapat tercapai secara maksimal. Menurut Direktorat Pembinaan Sekolah Menengah dan Atas (2010), bahan ajar adalah segala bentuk bahan berupa seperangkat materi yang disusun secara sistematis untuk membantu guru/instruktur dalam melaksanakan kegiatan pembelajaran dan memungkinkan peserta didik untuk belajar.

Berdasarkan informasi yang diperoleh melalui observasi awal yang dilakukan oleh peneliti di SMPIT Fajar Ilahi kelas VII pada awal bulan Januari sampai Februari 2017. Bahan ajar yang digunakan adalah buku teks yang berukuran besar yang diterbitkan oleh suatu penerbit tertentu sedangkan media pembelajaran yang sering digunakan dalam proses kegiatan pembelajaran yaitu papan tulis, proyektor serta lingkungan sekitar sekolah. Dalam hal ini peneliti ingin melakukan penelitian berupa pembuatan buku saku materi keanekaragaman makhluk hidup di SMPIT Fajar Ilahi Batam Tahun Pelajaran 2016/2017. Adapun tujuan dari penelitian ini adalah untuk mengetahui cara pembuatan buku saku dan mengetahui kelayakan buku saku materi Keanekaragaman Makhluk Hidup menurut validator, guru mata pelajaran IPA dan respon siswa di SMPIT Fajar Ilahi Batam. Menurut (Kamus Besar Bahasa Indonesia, 2012 dalam Gusmiati, 2015) buku saku adalah buku berukuran kecil yang dapat disimpan dalam saku dan mudah di bawa kemana-mana. Buku saku lebih nyaman untuk dibawa guru 
atau peserta didik karena ukurannya kecil. Diharapkan dengan adanya buku saku dapat membantu proses belajar mengajar di sekolah. Keanekaragaman makhluk hidup adalah suatu istilah yang menunjukkan sejumlah variasi yang ada pada makhluk hidup di suatu lingkungan tertentu.Keanekaragaman itu dapat terjadi karena adanya perbedaan ciri-ciri dari masing-masing makhluk hidup tersebut seperti sifat, warna, ukuran, bentuk, habitat, dan lain sebagainya.

\section{METODOLOGI}

Penelitian ini merupakan penelitian riset dan pengembangan atau Research and Development (R\&D).Sugiyono (2009) dalam Haryati (2012) berpendapat bahwa, metode penelitian dan pengembangan adalah metode penelitian yang digunakan untuk menghasilkan produk tertentu, dan menguji keektifan produk tersebut. Produk yang akan dibuat dalam penelitian ini adalah buku saku IPA Terpadu materi keanekaragaman makhluk hidup untuk peserta didik kelas VII di SMPIT Fajar Ilahi Batam. Dalam penelitian ini digunakan model penelitian dan pengembangan melalui ADDIE.ADDIE merupakan singkatan dari Analysis, Design, Development or Production, Implementation or Delivery and Evaluation. Model penelitian dan pengembangan ADDIE yang dilakukan adalah tiga tahap saja yaitu tahap Analysis, Design, dan Development or Production.

Penelitian ini dilakukan di kelas VII SMPIT Fajar Ilahi Batam dari bulan April hingga Mei 2017. Jenis data yang dikumpulkan dalam penelitian ini terdiri dari dua data yaitu data primer dan data sekunder. Data primer pada penelitian ini adalah data yang diperoleh melalui kuesioner atau angket penilaian kualitas produk oleh ahli materi, ahli media, guru mata pelajaran IPA Terpadu dan respon siswa sedangkan data sekunder pada penelitian ini adalah data literatur, data hasil ujian tengah semseter ganjil siswa, dan data hasilwawancara.

Pada penelitian ini menggunakan teknik analisa data dengan analisis deskriptif yang meliputi analisis kelayakan buku saku.

a. Memberikan skor jawaban dengan kriteria berdasarkan skala Likert: 
Tabel 1. Kriteria Penilaian Skala Likert Angket Validasi

\begin{tabular}{lc}
\hline \multicolumn{1}{c}{ Alternatif Jawaban } & Skor \\
\hline Sangat Baik & 5 \\
Baik & 4 \\
Ragu-ragu & 3 \\
Tidak Baik & 2 \\
Sangat Tidak Baik & 1 \\
\hline
\end{tabular}

b. Menentukan skortertinggi

Skor tertinggi $=$ jumlah validator $\mathrm{x}$ jumlah indikator $\mathrm{x}$ skor maksimum .

c. Menentukan jumlah skor dari masing-masing validator dengan menjumlahkan semua skor yang diperoleh dari masing-masingindikator.

d. Menentukan skor yang diperoleh dengan menjumlahkan skor dari masingmasingvalidator.

e. Penentuan nilai validitas dengan cara sebagaiberikut:

$$
\text { NilaiValiditas }=\quad \frac{\text { jumlah skor yang diperoleh }}{\text { Jumlah skor tertinggi }} \times 100 \%
$$

f. Selanjutnya memberikan penilaian validitas dengan kriteria sebagai berikut :

\begin{tabular}{|c|c|c|c|}
\hline Kategori & Persentase & Klasifikasi & Keterangan \\
\hline $\mathrm{A}$ & $100 \%-80 \%$ & Valid & $\begin{array}{l}\text { Produk siap dimanfaatkan di } \\
\text { lapangan untuk kegiatan } \\
\text { pembelajaran }\end{array}$ \\
\hline B & $79 \%-60 \%$ & Cukup Valid & $\begin{array}{l}\text { Produk dapat dilanjutkan } \\
\text { dengan menambahkan sesuatu } \\
\text { yang kurang dengan } \\
\text { pertimbangan-pertimbangan } \\
\text { tertentu }\end{array}$ \\
\hline $\mathrm{C}$ & $59 \%-50 \%$ & Kurang Valid & $\begin{array}{l}\text { Melakukan revisi dengan } \\
\text { meneliti kembali secara } \\
\text { seksama dan mencari } \\
\text { kelemahan-kelemahan produk } \\
\text { untuk diperbaiki }\end{array}$ \\
\hline $\mathrm{D}$ & $49 \%-0 \%$ & Tidak Valid & $\begin{array}{l}\text { Melakukan revisi secara besar- } \\
\text { besaran dan mendasar tenttang } \\
\text { isi produk }\end{array}$ \\
\hline
\end{tabular}

Tabel 2. Kriteria Penilaian Validitas

Sumber: (Sudjana dalam Salamah, 2014) 


\section{HASIL DAN PEMBAHASAN}

Penelitian ini menghasilkan produk berupa buku saku "Keanekaragaman Makhluk Hidup" untuk siswa kelas 7 SMPIT Fajar Ilahi Batam. Penelitian dan pengembangan ini dilakukan dengan model ADDIE sebagai berikut.

\section{Tahap Analisis (Analysis)}

Pada tahap awal yaitu dengan menganalisis kebutuhan untuk menentukan masalah dan solusi yang tepat bagi peserta didik. Hal-hal yang perlu dilakukan pada tahap analisis awal yaitu :

1) Analisiskurikulum.

Kurikulum yang diterapkan di SMPIT Fajar Ilahi Batam pada Tahun Pelajaran 2016/2017 adalah Kurikukulum Tingkat Satuan Pendidikan (KTSP). 2) Analisis masalah.

Analisis masalah didapat dari hasil wawancara dengan guru IPA Terpadu siswa kelas 7 SMPIT Fajar Ilahi Batam, adapun hasilnya sebagai berikut.

a. Peserta didik belum seluruhnya berhasil mencapai kriteria ketuntasan minimal belajar IPA dilihat dari hasil nilai UTS Ganjil peserta didik yang mencapai KKM sebesar $44 \%$ dan belum mencapai KKM sebesar $56 \%$.

b. Bahan ajar atau media pembelajaran yang sering digunakan dalam kegiatan pembelajaran terbatas pada buku paket, papan tulis, dan kadang-kadang proyektor.

c. Buku pelajaran yang tersedia dari sekolah berukuran relatif besar dan berat sehingga menyulitkan peserta didik untuk dibawa kemana-mana.

d. Belum tersedianya sarana dan prasarana belajar pendukung seperti perpustakaan yang lengkap di sekolah.

3) Analisis kebutuhan peserta didik.

Tahap ini dilakukan analisis kebutuhan terhadap hasil wawancara dengan guru. Diperlukan adanya pembuatan media pembelajaran, khususnya untuk mata pelajaran IPA Terpadu. Media diperlukan karena kurangnya sumber belajar yang tersedia di perpustakaan sekolah. Media yang dibuat berupa buku saku yang berisi materi pembelajaran tentang keanekaragaman makhluk hidup. Buku saku yang dibuat didesain dengan memuat ringkasan 
materi dilengkapi dengan gambar-gambar berwarna yang relevan, dilengkapi dengan adanya soal dan jawaban serta glosarium untuk memberikan efek menarik dan kemudahan siswa dalam memahami pelajaran. Selain itu peneliti juga menerima saran-saran dari ahli materi dan media supaya pada buku saku ditambahkan sumber gambar pada daftar pustaka, dan ditambahkan lampiran riwayat penulis.

\section{Tahap Perancangan (Design)}

Buku saku IPA materi keanekaragaman makhluk hidup dibuat dengan rancangan yang telah disusun sebagai berikut:

1. Ukuran buku saku yaitu $9,5 \mathrm{~cm}$ (lebar) x $16 \mathrm{~cm}$ (tinggi) dengan orientation portrait.

2. Jenis kertas yang digunakan ada dua yaitu kertas HVS 100gr dan kertas Glossy Photo Paper210gr.

3. Aplikasi komputer untuk mendesain menggunakan aplikasi Microsoft Office Publisher 2007, Corel Draw x8 Graphic, Power Point dan dengan bantuan aplikasi pemotong gambar Lightshot.

4. Bagian cover memuat identitas buku saku yang meliputi judul, materi, sasaran penggunaan dan penyusun buku saku serta beberapa gambar makhluk hidup.

5. Bagian isi buku dibuat dengan tampilan layout satu columns. Halaman diatur dengan margin: $1,0 \mathrm{~cm}$ (top), 0,254cm (left), 0,254cm (bottom), dan $0,254 \mathrm{~cm}$ (right).

6. Jenis huruf adalah Times New Roman dengan ukuran huruf 7pt.

7. Warna huruf dan gambar isi buku saku dicetak dengan mayoritas warna hitam dan beberapa bagian diberi warna.

8. Spasi yang digunakan untuk pengetikan isi buku saku adalah 1pt after paragraphs dan 0,69sp between lines.

\section{Tahap Pembuatan atau Pengembangan(Development)}

\subsection{Validasi Kelayakan Produk.}

Setelah buku saku materi keanekaragaman makhluk hidup selesai dicetak maka selanjutnya peneliti melakukan validasi buku saku. Adapun ahli materi dalam penelitian ini adalah Ibu Fenny Agustina, S.Pt.M.Si sedangkan 
ahli media adalah Ibu Rahmi, S.Pd, M.Pd. yang merupakan dosen di FKIP Universitas Riau Kepulauan Batam. Berikut secara ringkas, rekapitulasi hasil validasi disajikan dalam tabel berikut ini.

Tabel 3.Rekapitulasi Hasil Validasi Buku Saku IPA Materi Keanekaragaman Makhluk Hidup oleh Ahli Materi.

\begin{tabular}{clllll}
\hline No & $\begin{array}{l}\text { Aspek } \\
\text { Kelayakan }\end{array}$ & Jumlah Skor & Total Skor & Nilai Validitas & Kategori \\
\hline 1 & Isi & 42 & \multirow{2}{*}{68} & 84,00 & Valid \\
2 & Kebahasaan & 26 & & 74,29 & Cukup \\
\hline & RATA-RATA & & & $\mathbf{8 0 , 0 0}$ & Valid \\
\hline
\end{tabular}

Berdasarkan dari tabel rekapitulasi hasil validasi buku saku materi keanekaragaman makhluk hidup oleh ahli materi, diketahui bahwa nilai validitas 80,00 terletak pada rentang persentase $100 \%$ - $80 \%$ yang berarti bahwa media yang dibuat mendapat nilai "A" dengan kategori“Valid".

Tabel 4.Rekapitulasi Hasil Validasi Buku Saku IPA Materi Keanekaragaman Makhluk Hidup oleh Ahli Media.

\begin{tabular}{llllll}
\hline No & $\begin{array}{l}\text { Aspek } \\
\text { Kelayakan }\end{array}$ & $\begin{array}{l}\text { Jumlah } \\
\text { Skor }\end{array}$ & $\begin{array}{l}\text { Total } \\
\text { Skor }\end{array}$ & $\begin{array}{l}\text { Nilai } \\
\text { Validitas }\end{array}$ & Kategori \\
\hline 1 & Penyajian & 21 & 52 & 84,00 & Valid \\
2 & Kegrafikaan & 31 & 58,89 & Cukup \\
\hline & RATA-RATA & & & $\mathbf{7 4 , 2 9}$ & Cukup Valid \\
\hline
\end{tabular}

Berdasarkan dari tabel rekapitulasi hasil validasi buku saku materi keanekaragaman makhluk hidup oleh ahli media, diketahui bahwa nilai validitas 74,29 terletak pada rentang persentase 79\% - 60\% yang berarti bahwa media yang dibuat mendapat nilai "B" dengan kategori "cukupvalid".

Tabel 5. Rekapitulasi Hasil Validasi Buku Saku IPA Materi Keanekaragaman Makhluk Hidup oleh Guru IPA Terpadu.

\begin{tabular}{llllll}
\hline No & $\begin{array}{l}\text { Aspek } \\
\text { Kelayakan }\end{array}$ & Jumlah Skor & Total Skor & Nilai Validitas & Kategori \\
\hline 1 & Isi & 83 & & 83,00 & Layak \\
2 & Kebahasaan & 52 & 245 & 74,29 & Cukup \\
3 & Penyajian & 41 & & 82,00 & Layak \\
4 & Kegrafikaan & 69 & & 76,67 & Cukup \\
\hline & RATA-RATA & & $\mathbf{7 9 , 0 3}$ & cukup \\
& & & & valid \\
\cline { 3 - 5 }
\end{tabular}

Berdasarkan dari tabel rekapitulasi hasil validasi buku saku materi keanekaragaman makhluk hidup oleh guru IPA Terpadu, diketahui bahwa nilai 
validitas sebesar 79,03 terletak pada rentang 79\% - 60\% yang berarti bahwa media yang dibuat mendapat nilai "B" dengan kategori "cukup valid".

Tabel 6. Perbandingan Hasil Validasi Buku Saku IPA Materi Keanekaragaman Makhluk Hidup oleh Ahli Materi, Ahli Media dan Guru IPA Terpadu.

\begin{tabular}{llllllll}
\hline No & $\begin{array}{l}\text { Aspek } \\
\text { Kelayakan }\end{array}$ & \multicolumn{3}{c}{ Validator } & $\begin{array}{l}\text { Nilai } \\
\text { Validitas }\end{array}$ & Nilai & Kategori \\
& & $\begin{array}{l}\text { Ahli } \\
\text { Materi }\end{array}$ & $\begin{array}{l}\text { Ahli } \\
\text { Media }\end{array}$ & $\begin{array}{l}\text { Guru } \\
\text { IPA }\end{array}$ & & & \\
\hline 1 & Isi & 84,00 & & 83,00 & 83,50 & A & Valid \\
2 & Kebahasaan & 74,29 & & 74,29 & 74,29 & B & Cukup \\
3 & Penyajian & & 84,00 & 82,00 & 83,00 & A & Valid \\
4 & Kegrafikaan & & 68,89 & 76,67 & 72,78 & B & Cukup \\
\hline & RATA-RATA & & & & & B & cukup \\
& & & & & & \\
\cline { 4 - 7 }
\end{tabular}

\section{Revisi Produk}

Perbaikan atau revisi dilakukan untuk meminimalisir kesalahankesalahan dalam pembuatan buku saku dan menjadikan buku saku layak untuk diujicobakan.

a. Perbaikan Aspek Kelayakan Isi

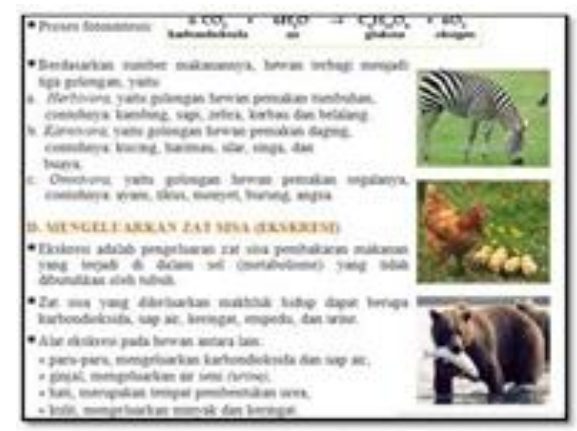

Gambar 1. Layout dan gambar sebelum revisi

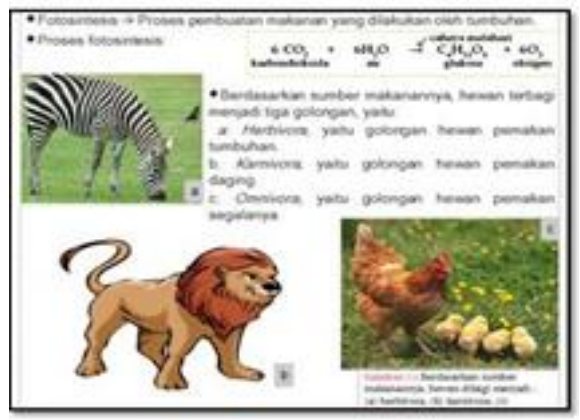

Gambar 2. Layout dan gambar sesudah revisi 
b. Perbaikan Aspek Kelayakan Kebahasaan
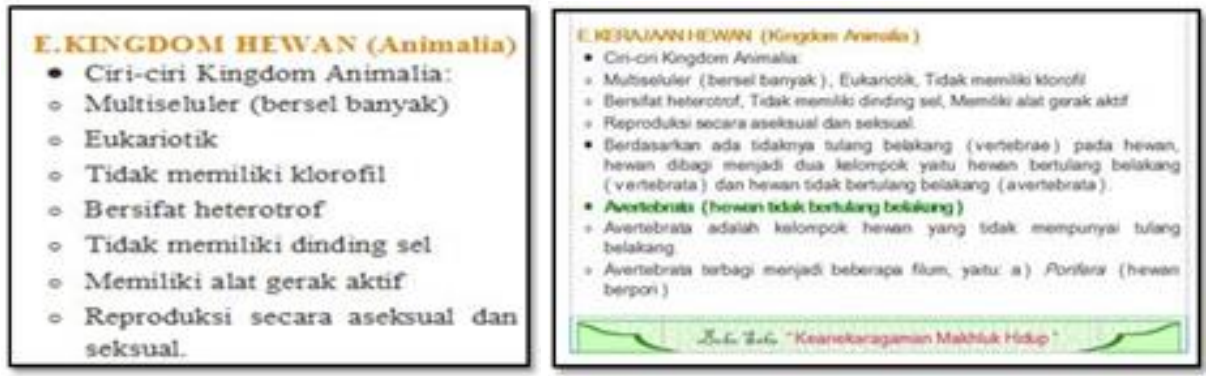

Gambar 3. Penggunaan bahasa sebelum revisi (kiri) dan sesudah revisi (kanan)

c. Perbaikan Aspek Kelayakan Penyajian
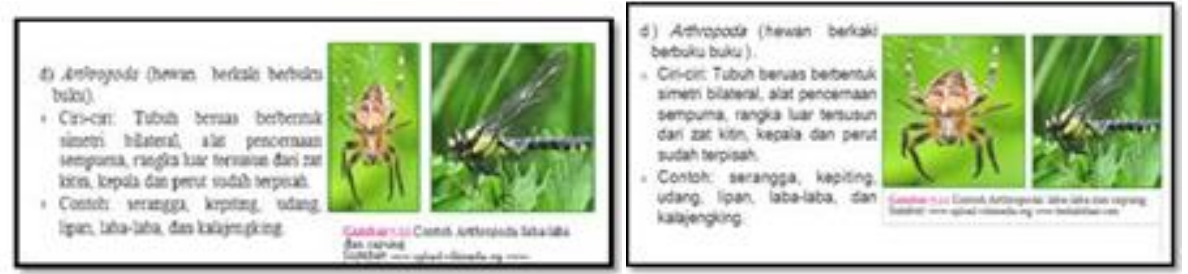

Gambar 4. Penggunaan gambar sebelum revisi (kiri) dan sesudah revisi (kanan)

d. Perbaikan Aspek Kelayakan Kegrafikaan
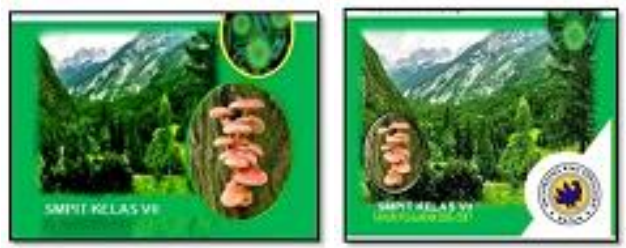

Gambar 5. Penambahan logo Unrika sebelum revisi (kiri) dan sesudah revisi (kanan)

\subsection{Respon atau penilaian siswa terhadap buku saku Materi Keanekargaman Makhluk Hidup}

Uji coba produk buku saku dilakukan terhadap siswa kelas VII Putra dan kelas VII Putri SMPIT Fajar Ilahi Batam yang berjumlah 52 siswa. Adapun rekapitulasi hasil penilaian buku saku oleh siswa sebagaiberikut:

Tabel 7. Rekapitulasi Penilaian Siswa Terhadap Buku Saku IPA Materi Keanekaragaman Makhluk Hidup oleh Ahli Media.

\begin{tabular}{clll}
\hline No & Nomor Instrumen & Rata-rata Validitas & Kategori \\
\hline 1 & Isi & 91,22 & Valid \\
2 & Kebahasaan & 87,56 & Valid \\
3 & Penyajian & 92,16 & Valid \\
4 & Kegrafikaan & 89,72 & Valid \\
\hline & RATA-RATA & & Valid \\
\hline
\end{tabular}


Berdasarkan hasil keseluruhan penilaian siswa terhadap buku saku Materi Keanekaragaman Makhluk Hidup menunjukkan bahwa buku saku yang dibuat berdasarkan aspek kelayakan isi, aspek kelayakan kebahasaan, aspek kelayakan penyajian dan aspek kelayakan kegrafikaan maka buku saku yang telah dibuat "Valid/Layak" untuk digunakan. Dengan demikian Buku Saku IPA materi Keanekaragaman Makhluk Hidup ini layak digunakan sebagai media atau sumber belajar siswa kelas VII SMPIT Fajar Ilahi Batam.

\section{KESIMPULAN DAN SARAN}

1. Kesimpulan

Berdasarkan hasil penelitian dan pembahasan dapat diambil kesimpulan bahwa:

1) Pembuatan media buku saku IPA Terpadu telah melalui 3 tahap, yaitu:

Tahap Analisis (Analysis), Tahap Perancangan (Design), dan Tahap

Pembuatan atau Pengembangan (Development).

2) Tingkat kelayakan buku saku IPA Terpadu diketahui berdasarkan penilaian dari satu Ahli Materi, satu Ahli Media dan dua guru IPA Terpadu dilihat dari aspek kelayakan isi, kebahasaan, penyajian dankegrafikaan.

a. Penilaian kelayakan oleh Ahli Materi diperoleh nilai validitas sebesar 80,00 dimana termasuk dalam kategori "Layak".

b. Penilaian kelayakan oleh Ahli Media diperoleh nilai validitas sebesar 74,29 dimana termasuk dalam kategori "CukupLayak".

c. Penilaian kelayakan oleh guru IPA Terpadu diperoleh nilai validitas sebesar 79,03 dimana termasuk dalam kategori "CukupLayak".

d. Respon atau penilaian siswa kelas VII SMPIT Fajar Ilahi Batam terhadap buku saku IPA Terpadu materi keanekaragaman makhluk hidup dilihat dari aspek kelayakan isi, kebahasaan, penyajian dan kegrafikaan menunjukkan perolehan nilai validitas sebesar 90,11 dimana termasuk dalam kategori "Layak".

e. Berdasarkan hasil respon atau penilaian siswa kelas VII SMPIT Fajar Ilahi Batam terhadap buku saku IPA Terpadu materi keanekaragaman makhluk hidup dilihat dari aspek kelayakan isi, kebahasaan, penyajian dan kegrafikaan menunjukkan perolehan nilai validitas sebesar 90,11 dimana termasuk dalam kategori "Layak". Maka buku saku IPA 
Terpadu materi keanekaragaman makhluk hidup yang telah dibuat layak untuk digunakan sebagai sumber belajar atau media pembelajaran.

2. Saran

Berdasarkan hasil penelitian yang telah dijelaskan, Buku Saku IPA Terpadu sebagai sumber belajar tambahan masih memiliki banyak kelemahan. Berikut ini beberapa saran-saran yang diperlukan antara lain:

1). Waktu yang digunakan untuk penelitian dan pengembangan sebaiknya diperpanjang, mulai dari tahap analisis sampai pada tahap pembuatan dan uji coba produk supaya produk yang dihasilkan dapat lebih baik lagi.

2). Materi pada buku saku IPA Terpadu dapat dikembangkan lebih luas lagi dengan menambahkan kompetensi dasar yang lain.

3). Perlunya dilakukan penelitian lebih lanjut seperti penelitian eksperimen atau penelitian tindakan kelas agar dapat diketahui efektivitas dari penggunaan buku saku IPA Terpadu.

\section{REFERENSI}

Ahmad, Z. A. (2012). Perencanaan Pembelajaran dari Desain sampai Implementasi. Yogyakarta: Pedagogia.

Arsyad, A. (2011). Media Pembelajaran (15th ed.). Jakarta: Rajawali Pers.

Arikunto, S. (2013). Cara Dahsyat Membuat Skripsi. (Cetakan 1). Madiun: Jaya Star Nine.

Asyhari, A. (2016). Pengembangan Media Pembelajaran Berupa Buletin Dalam Bentuk Buku saku Untuk Pembelajaran IPA Terpadu.Jurnal Ilmiah Pendidikan Fisika 'Al-Biruni'. 5: 1-13.

Dantes, N. (2012). Metode Penelitian. (Pertama). Yogyakarta: C.V Andi Offset. Daryanto.(2010). Media Pembelajaran. Yogyakarta: Penerbit Gava Media Gusmiati. (2015). Pengembangan Media Pembelajaran Berbentuk Buku Saku Dilengkapi Peta Konsep Pada Materi Ekosistem untuk Siswa Kelas VII SMPN 3 Gunung Tuleh, artikel diunduh tanggal 21 Februari 2017, dari www.ejurnal.bunghatta.ac.id/index.php?journal=JFKIP\&page=article\&op..

Jihad, A dan A. Haris.(2013). Evaluasi Pembelajaran. (1st ed.). Yogyakarta: Multi Pressindo.

Lufri dan Arlis dkk.(2007). Strategi Pembelajaran Biologi. Padang: Universitas Negeri Padang.

Meikahani, Ranintya dan E. S. Kriswanto.(2015). Pengembangan Buku Saku Pengenalan Pertolongan Dan Perawatan Cedera Olahraga Untuk Siswa Sekolah Menengah Pertama.Jurnal Pendidikan Olahraga Fakultas Ilmu Keolahragaan Universitas Negeri Yogyakarta.11:15-22

Munadi, Y. (2012). Media Pembelajaran (4th ed.). Jakarta: Gaung Persada Press. 
Mutmainah.(2014). Buku Saku Keanekaragaman Hayati Hasil Inventarisasi Tumbuhan Berpotensi Tanaman Hias Di Gunung Sari Singkawang.Jurnal Pendidikan dan Pembelajaran.3:1-12

Purwanto, R. (2011). Peningkatan Motivasi dan Hasil Belajar Siswa pada

Kompetensi Sistem Koordinasi Melalui Metode Pembelajaran Teaching

Game Team terhadap Siswa Kelas XI IPA SMA Smart Ekselensia Indonesia

Tahun Ajaran 2010-2011.Jurnal Pendidikan Dompet Dhuafa. 1: 1-14.

purwoko,. A. Sulistyorini dan W. Prihantini. (2008). IPA Terpadu SMP Kelas VII (edisi pertama). Jakarta: Yudhistira.

Setyono, Y. A. (2013). Pengembangan Media Pembelajaran Fisika Berupa Buletin Dalam Bantuk Buku Saku Untuk Pembelajaran Fisika Kelas VIII Materi Gaya Ditinjau Dari Minat Baca Siswa. Jurnal Pendidikan Fisika FKIP UNS. 1: 118-126.

Haryati, S. (2012).Research and Development (R\&D) Sebagai Salah Satu Model Penelitian Dalam Bidang Pendidikan. Artikel diunduh tanggal 7 Maret 2017 dari http://download.portalgaruda.org/article.php?article=60637\&val=4518

Sujarweni, V. W. (2014). Metodologi Penelitian Keperawatan (1st ed.).

Yogyakarta: Penerbit Gava Media.

Sujarweni, V. W. (2015). SPSS Untuk Penelitian. (1st ed.). Yogyakarta: Pustaka Baru Press

Suparno, P. (2014). Metode Penelitian Pendidikan IPA. (Cetakan Pertama).

Yogyakarta: Penerbit Universitas Sanata Dharma. 